\title{
Ortodoncia y periodoncia
}

\section{Orthodontics and periontics}

\author{
Tortolini P*, Fernández Bodereau E**
}

\section{RESUMEN}

El paciente periodontal se puede beneficiar con un tratamiento combinado de ortodoncia y periodoncia, ya que determinados movimientos dentarios como la extrusión, la intrusión, la rotación, el enderezamiento, etc pueden ser favorables para el periodonto enfermo.

Lo que es fundamental antes de empezar el tratamiento de ortodoncia de un paciente periodontal es eliminar la inflamación activa de los tejidos.

Palabras clave: Inflamación, fuerzas, movimientos ortodóncicos, higiene oral.

\section{SUMMARY}

Periodontal patients can benefit from a combined treatment of orthodontics and periodontics, because certain tooth movements as extrusión, intrusion, rotation, straightening, etc. may be favorable for the periodontal patient.

Which is essential before starting orthodontic treatment of a periodontal patient is to eliminate active inflammation of the tissues.

Key words: Inflammation. Forces, orthodontic movements, oral hygiene.

Fecha de recepción: 10 de febrero de 2010.

Aceptado para publicación: 18 de marzo de 2010.

* Profesor Asistente Cátedra Periodoncia de la Facultad de Odontología. Universidad Nacional de Córdoba. Argentina.

** Catedrático de Clínica de Prótesis de la Facultad de Odontología. Universidad Nacional de Córdoba. Argentina.

Tortolini P, Fernández Bodereau E. Ortodoncia y periodoncia. Av. Odontoestomatol 2011; 27 (4): 197-206.

\section{INTRODUCCIÓN}

Los tejidos de la cavidad oral están estrechamente interrelacionados, por lo tanto, cuando alguno de ellos enferma, el resto se puede afectar en grado variable dependiendo de su relación funcional y de proximidad física.

El ortodoncista y el periodoncista pueden colaborar en distintos campos, ya que ambas especialidades comparten situaciones clínicas y objetivos.
Cuando la salud oral del paciente es buena, el objetivo común de los dos especialistas es mantenerla, y si es posible, mejorar la función de longevidad y estética del aparato estomatognático. Cuando no lo es, el ortodoncista ha de subordinar los objetivos oclusales y estéticos a su recuperación.

Aunque el periodoncista se dedica fundamentalmente a tratar las enfermedades inflamatorias de los tejidos de soporte dentario, también trabaja sobre los mismos con fines estéticos. Además, puede prevenir 
la aparición de problemas periodontales relacionados con los movimientos ortodóncicos y tratar sus complicaciones. Como la periodoncia se centra sobre todo en el paciente adulto, se relaciona bien con la ortodoncia actual, qué, en las últimas décadas, ha incorporado a pacientes de todas las edades.

Al tratar adultos, el ortodoncista tendrá nuevos retos, como tratar a pacientes periodontales, en los cuales las condiciones muchas veces, no son las más favorables porque habrán ya perdido elementos o hay elementos con soporte reducido; en contraposición tendremos un paciente más colaborador y que controla, por lo general, mejor la placa que un paciente infantil y/o adolescente, quienes además presentan cambios hormonales que pueden potenciar los fenómenos inflamatorios.

Con la aparición de la adhesión directa, los brackets cerámicos y la ortodoncia lingual, mayor número de adultos acepta el tratamiento ortodóntico. Esto ha cambiado la manera de trabajar de muchos ortodoncistas y ello ha aportado también nuevas necesidades de tratamiento y nuevas consideraciones.

Se han desarrollado últimamente nuevos brackets cerámicos, cuyo uso parece ser prometedor, ya que son de valor neutro, lo cual los hace más aceptables estéticamente. Se adhieren y liberan con facilidad, al mismo tiempo que proveen un buen anclaje para el arco.

La ortodoncia lingual ha significado un avance interesante en cuanto a la estética ortodóncica, pero presenta problemas biomecánicos importantes como que la eficiencia del arco disminuye considerablemente debido al menor radio de curvatura de la superficie lingual con respecto a la vestibular.

En cualquier caso, si se considera necesario realizar una intervención quirúrgica con el fin de reducir el riesgo de recesiones de los tejidos blandos deberemos estar más atentos a conseguir aumentar el espesor del tejido y no tanto el ancho apicocoronal de la encía.

Las técnicas quirúrgicas usadas en estos casos son los injertos gingivales, siendo utilizados habitualmente las técnicas de injerto libre e injerto subepitelial.
Describiremos el manejo de los tejidos blandos periodontales en distintas situaciones antes, durante y después del tratamiento ortodóncico, con técnicas periodontales quirúrgicas relativamente sencillas con las que se puede conseguir un buen nivel de función y estética de los tejidos blandos en los pacientes periodontalmente sanos o con enfermedad periodontal que están recibiendo o han recibido tratamiento ortodóncico.

Al planificar cualquier tratamiento de ortodoncia, el ortodoncista tiene en cuenta la situación actual de los tejidos óseos y dentarios y su evolución previsible con el fin de conseguir el mejor efecto terapéutico. Sin embargo, no debería excluir de su sistemática la valoración de los tejidos blandos periodontales, elemento esencial sin el que resulta imposible alcanzar la excelencia en los resultados.

En primer lugar, hay que establecer si el complejo del periodonto de protección va a permitir el mantenimiento de la salud periodontal, antes, durante y después del tratamiento de ortodoncia. Para ello se deben valorar las características físicas de los tejidos gingivales, su grado de inflamación y si existe una cantidad suficiente de encía insertada capaz de soportar el tratamiento de ortodoncia y sus consecuencias en el futuro.

\section{BASES BIOLÓGICAS DEL TRATAMIENTO ORTODÓNCICO}

Para comprender cabalmente la respuesta periodontal a las fuerzas ortodóncicas creemos conveniente recordar el comportamiento biológico de los tejidos sobre los que actuamos.

El tratamiento ortodóntico se basa en el principio de que, si se aplica una presión prolongada sobre un diente, se producirá una movilización del mismo al remodelarse el hueso que lo rodea. El hueso desaparece selectivamente de algunas zonas y va añadiéndose a otras.

El diente se desplaza a través del hueso arrastrando consigo su aparato de anclaje, al producirse la migración del alveolo dental. Así el movimiento es un fenómeno de dicho ligamento (1). 


\section{Respuesta del ligamento periodontal a la función normal}

Durante la masticación, los dientes y las estructuras periodontales soportan fuerzas intensas e intermitentes. Al masticar alimentos blandos se aplican fuerzas de 1 a $2 \mathrm{Kg}$ y con alimentos más resistentes hasta $50 \mathrm{Kg}$.

Cuando un diente se ve sometido a sobrecarga de este tipo la presión se transmite por el ligamento periodontal y el liquido hístico incompresible evita el rápido desplazamiento del diente en el espacio del ligamento periodontal, y la fuerza se transmite al hueso alveolar, el que se deforma en respuesta a la misma, y cada diente se desplaza ligeramente (2).

El ligamento periodontal está adaptado a fuerzas de poca duración, cuando las fuerzas son prolongadas ese empuje del diente contra el alveolo genera el inicio de la remodelación ósea, aunque la fuerza no sea muy intensa. La movilización ortodóncica se logra con fuerzas prolongadas y suaves.

Los tejidos blandos como labios, lengua y mejillas constituyen estructuras musculares que actúan generando fuerzas sobre los dientes, estas presiones no suelen estar equilibradas, pero no mueven a los dientes por la compensación que hace el ligamento periodontal con su efecto metabólico, según Proffit (1). Una consecuencia de este concepto sería que las personas con secuelas de una enfermedad periodontal avanzada, requerirán contención permanente después de la corrección ortodóncica.

\section{Respuesta del ligamento periodontal y el hueso a las fuerzas ortodóncicas mantenidas}

La respuesta de estos tejidos depende directamente de la intensidad y duración de las fuerzas aplicadas.

La fuerza máxima para que un diente se mueva sin interrumpir la irrigación capilar del ligamento periodontal es de $26 \mathrm{~g}$ por $\mathrm{cm}^{2}$. No debe superarse.

Si la fuerza aplicada sobre el diente tiene una intensidad suficiente como para oprimir totalmente la luz de los capilares sanguíneos de algunas zonas del ligamento periodontal, allí el corte de suministro de sangre produce una necrosis aséptica en la zona comprimida.

Por su aspecto histológico tras la desaparición de las células, se llamaba tradicionalmente zona hialinizada, que nada tiene que ver con la formación de tejido conjuntivo hialino. Entonces células procedentes de regiones vecinas intactas deben remodelar el hueso.

Adyacente a la zona necrosada, aparecen osteoclastos que atacan la base ósea necrosada del ligamento periodontal. Este proceso se llama reabsorción basal. Cuando este se produce se retrasa inevitablemente el movimiento dental, lo cual se debe a una demora en el estimulo para la diferenciación de las células y además porque hay que eliminar un considerable espesor de hueso antes de que el diente pueda moverse.

En movimientos ortodóncicos correctos se debe lograr el mayor movimiento dentario con fuerzas leves compatibles con la vitalidad de las células del ligamento periodontal, relativamente indoloro y con una remodelación ósea alveolar a partir de un mecanismo de reabsorción frontal.

Incluso con fuerzas leves, pueden aparecer pequeñas zonas avasculares en el ligamento y retrasar el movimiento dental, hasta que sean eliminadas mediante reabsorción basal.

La suave progresión del movimiento dental con una fuerza de poca intensidad puede resultar un ideal inalcanzable. En la práctica, el movimiento dental se suele producir en forma escalonada, debido a la inevitable formación de zonas de reabsorción basal. No obstante las fuerzas excesivas no tienen ninguna utilidad (3).

\section{TRATAMIENTO ORTODÓNCICO EN PACIENTE CON ENFERMEDAD PERIODONTAL}

Debemos partir de la base que los objetivos terapéuticos serán mas limitados. Es fundamental abordar cada caso interrelacionando las distintas áreas. En este marco se hace indispensable realizar un diagnostico exhaustivo y completo, para arribar a un plan terapéutico interdisciplinario. 
Ante estos pacientes el ortodoncista se enfrenta a un desafió, donde es prudente individualizar cada caso, ordenar las prioridades y establecer las posibilidades terapéuticas.

\section{Factores a considerar}

- Edad del paciente: no es contraindicación para la ortodoncia, pero es más fácil que se produzcan fenómenos de hialinización, ya que con los años disminuye la actividad celular y los tejidos se vuelven más ricos en colágeno, la respuesta tisular es más lenta, por lo que los movimientos deben ser más suaves.

- Existencia de patologías generales: como la diabetes, sobretodo si es un paciente descompensado. Esta afección metabólica, muchas veces, va asociada a enfermedad periodontal y como describiremos mas adelante, los tejidos inflamados de una periodontitis activa contraindican el movimiento ortodóntico. De modo similar los pacientes con H.I.V. suelen tener mayor complicación de las afecciones infecciosas como la periodontitis.

- Estados fisiológicos como el embarazo: donde las influencias hormonales favorecen al desarrollo de gingivitis gestacional o complicar una periodontitis preexistente.

- Factores locales como el tabaquismo: constituye un riesgo potencial para recidiva de una enfermedad periodontal tratada. Los tejidos siempre están inflamados.

- Motivación del paciente: es muy importante la actitud del paciente frente a su problema; si conoce lo que padece y la posible evolución de la enfermedad. La colaboración del paciente constituye un factor decisivo para continuar el tratamiento interdisciplinario o dar por concluido el mismo. El éxito del tratamiento se ve influenciado en gran medida por los hábitos de higiene bucal (4).

\section{Indicaciones y contraindicaciones del tratamiento ortodóncico en pacientes periodontales}

\section{Indicaciones}

Existen tres tipos de alteraciones en la posición de los dientes susceptibles de tratamiento ortodóncico en el paciente periodontal:

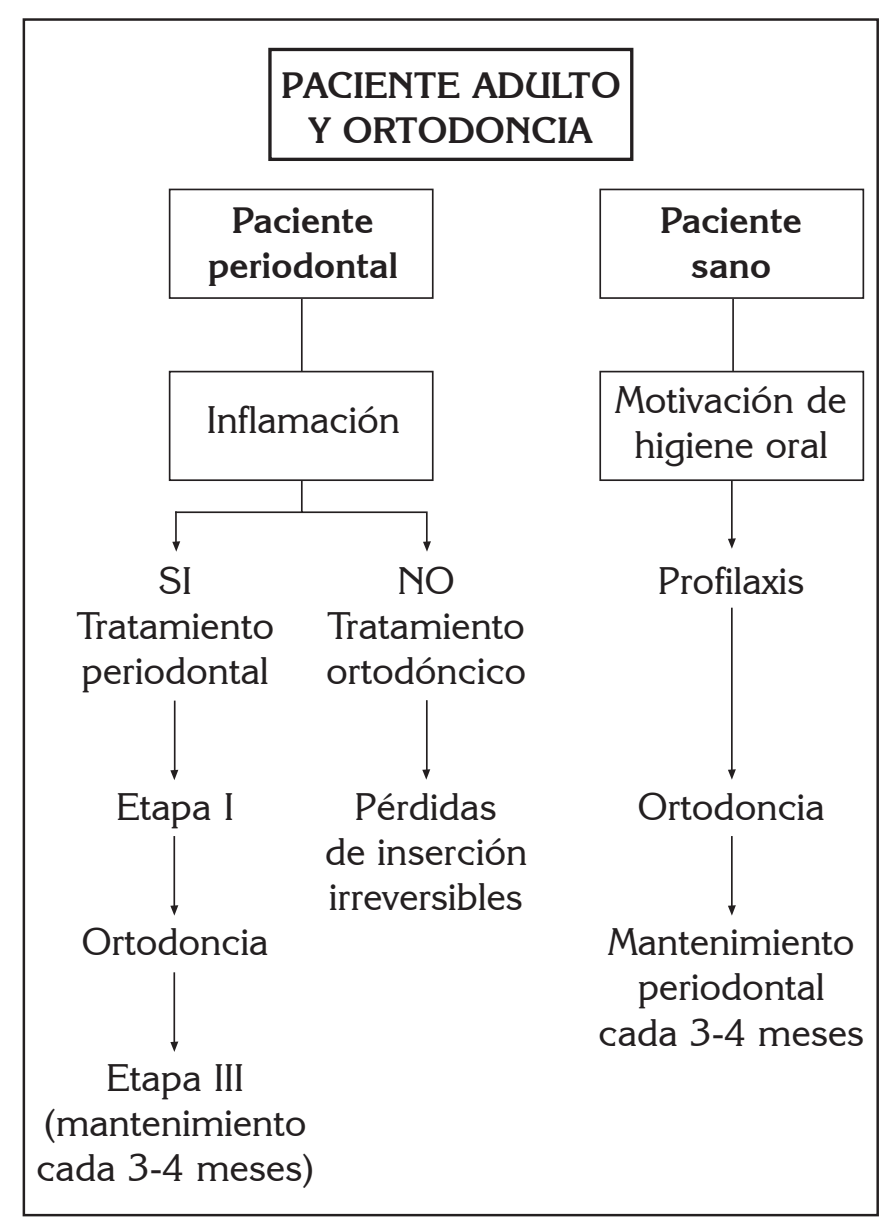

Gráfico de movimientos ortodóncicos en adultos (2).

- Malposiciones que ya estaban al finalizar la erupción definitiva (Fig. 5).

- Migraciones dentarias secundarias a parafunciones orales.

- Migraciones producidas por periodontitis.

Cualquiera de ellos justifica un tratamiento ortodóncico, una vez tratada la afección periodontal.

Entonces la ortodoncia está indicada con el objeto de:

- Mejorar la posición de los dientes y facilitar la realización de prótesis (Figs. 1-3).

- Distribuir adecuadamente las cargas oclusales para reducir el trauma oclusal y la movilidad dentaria (Fig. 4).

- Mejorar la estética, reduciendo los espacios negros interdentarios. 
- Mejorar la topografía ósea:

- Moviendo dientes hacia zonas de mayor volumen óseo.

- Alejando dientes de una lesión intraósea.

- Intruyendo dientes extruídos por la periodontitis (Fig. 1).

- Extruyendo dientes para conseguir mayor soporte alveolar (5) (Fig. 3).

- Enderezando molares inclinados mesialmente.

- Tratar sobremordidas profundas.

- Tratar mordidas cruzadas anteriores funcionales.

- Tratar malposiciones con defectos mucogingivales (6).

- Tratar mordidas abiertas acentuadas.

- Tratar impactación de alimentos por malposición.
- Tratar hiperplasia gingival fibrosa que causa desplazamientos dentarios.

\section{Contraindicaciones}

- Falta de control de la inflamación del periodonto. Si se mueven los dientes en presencia de inflamación se produce pérdida de hueso, acelerándose la evolución de la periodontitis activa.

- Falta de control oclusal (traumatismo oclusal, parafunciones) en individuos periodontalmente susceptibles.

- Imposibilidad de retención de los dientes después del tratamiento, displasias esqueléticas graves o problemas de hábitos musculares.

\begin{tabular}{|l|l|}
\hline \multicolumn{1}{|c|}{ INDICACIONES } & APARATOS Y MOVIMIENTO DENTARIO \\
\hline $\begin{array}{l}\text { 1. Topografía gingival adversa, proximidad radicular, } \\
\text { espacio de tronera, contactos abiertos, falta de } \\
\text { paralelismo, mala distribución de los pilares. }\end{array}$ & $\begin{array}{l}\text { Aparatos fijos; alineamiento, inclinación y } \\
\text { traslación. }\end{array}$ \\
\hline $\begin{array}{l}\text { 2. Incompetencia labial, falta de guía incisal. } \\
\text { 3. Discrepancia de marcas bucolinguales previniendo el } \\
\text { desgaste selectivo para la estabilidad y distribución de } \\
\text { la fuerza. }\end{array}$ & $\begin{array}{l}\text { Aparatos fijos y removibles; retracción, } \\
\text { inclinación, torque. }\end{array}$ \\
\hline $\begin{array}{l}\text { 4. Curva de Spee grave y un esquema oclusal cerrado } \\
\text { con traumatismo oclusal o necesidades restaurativas. }\end{array}$ & Aparatos fijos: nivelación del plano oclusal. \\
\hline $\begin{array}{l}\text { 5. Dientes inclinados gravemente. } \\
\text { 6. Traumatismo oclusal con pseudo Clase III con mordida } \\
\text { cruzada anterior, mordida cruzada posterior, contactos y y } \\
\text { primarios en relación céntrica. }\end{array}$ & Aparatos fijos: enderezamiento, inclinación. \\
\hline $\begin{array}{l}\text { 7. Mejoramiento de defectos gingivales y óseos, } \\
\text { proporción corona-raíz pobre, hueso interdentario } \\
\text { desnivelado. }\end{array}$ & $\begin{array}{l}\text { Aparatos fijos: erupción, inclinación, } \\
\text { intrusión. }\end{array}$ \\
\hline $\begin{array}{l}\text { 8. Mordidas profundas anteriores traumatismo oclusal } \\
\text { con traumatismo gingival, mordidas cerradas. }\end{array}$ & Aparatos fijos: intrusión. \\
\hline $\begin{array}{l}\text { 9. Mordidas abiertas anteriores y traumatismo oclusal con } \\
\text { falta de guía incisal anterior. }\end{array}$ & $\begin{array}{l}\text { Aparatos fijos y removibles: erupción, } \\
\text { retracción. }\end{array}$ \\
\hline $\begin{array}{l}\text { 10. Traumatismo oclusal excesivo / movilidad excesiva, } \\
\text { espasmo muscular, posición retrusiva de contacto (RC) } \\
\text { grave, discrepancia de la posición de máxima } \\
\text { intercuspidación, necesidad de establecer una } \\
\text { dimensión vertical, necesidad de desgaste selectivo. }\end{array}$ & $\begin{array}{l}\text { Plano de mordida Hawley para erupción } \\
\text { oclusal, reposo y reducción de la } \\
\text { hiperactividad muscular. }\end{array}$ \\
\hline
\end{tabular}




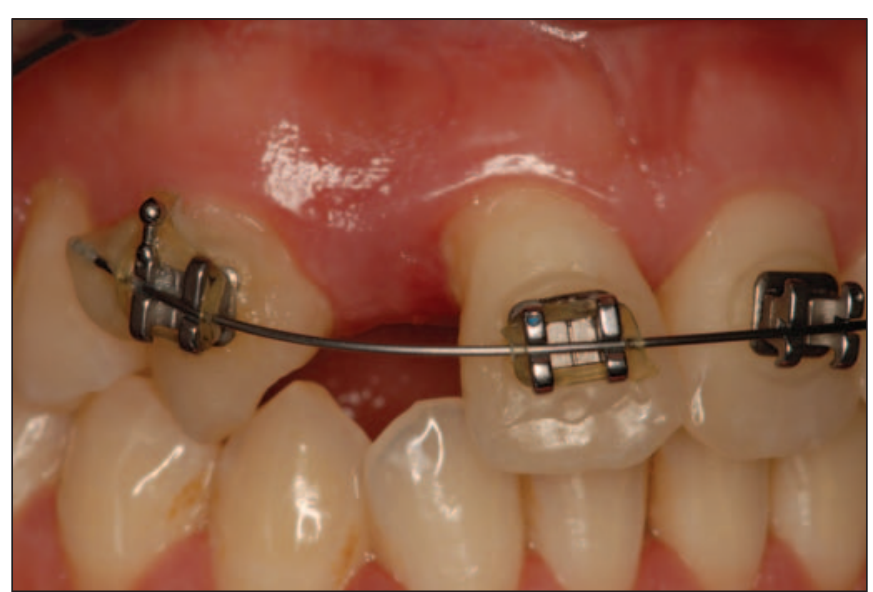

Fig. 1. Paciente joven con agenesia de IL, se realizan movimientos ortodóncicos (intrusión) para posicionarlo y colocar un implante.

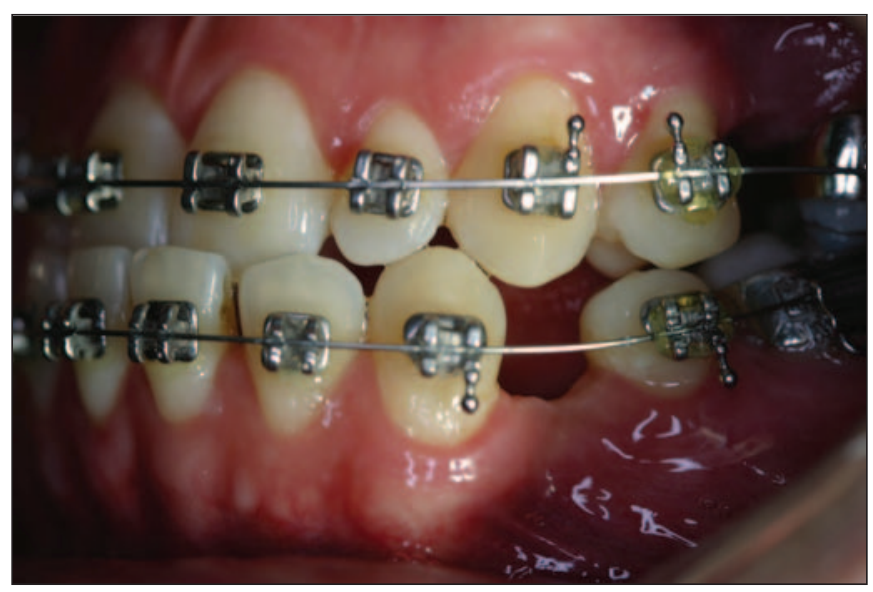

Fig. 2. Tratamiento de ortodoncia para corregir la mordida invertida y cierre de espacios, mediante la retrusión del sector anteroinferior.

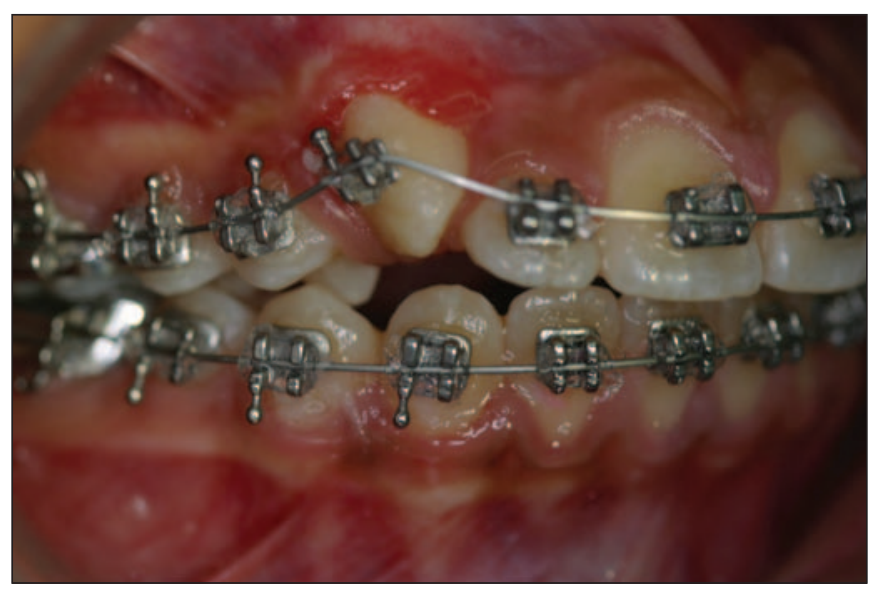

Fig. 3. Se realizan movimientos ortodóncicos (extrusión) para lograr posicionar al C para una correcta alineación dentaria.
Si bien la inflamación contraindica el tratamiento ortodóncico hay otros factores locales, ambientales y personales que constituyen contraindicaciones relativas ya que son factores de riesgo de fracaso terapéutico. Ellos son:

- Movilidad dentaria tipo III.

- Perdida ósea mayor al $75 \%$.

- Raíces cortas o reabsorción radicular idiopática.

- Lesión de furca tipo II y III.

- Historia de abscesos repetidos

- Historia de periodontitis agresiva.

- Mala higiene.

- Tabaquismo (más de diez cigarrillos por día).

- Mantenimiento profesional inadecuado (7).

\section{MOVIMIENTO DENTAL ORTODÓNCICO EN PACIENTES CON DESTRUCCIÓN DEL TEJIDO PERIODONTAL}

\section{Consideraciones}

El tratamiento ortodóncico mal ejecutado puede contribuir a agravar la destrucción del tejido periodontal. En particular, la combinación de inflamación, fuerzas ortodóncicas y trauma oclusal. Sin embargo cuando el tratamiento se realiza en forma correcta, se puede efectuar un tratamiento ortodóncico en el adulto con periodonto reducido pero sano sin deterioro periodontal adicional. Estudios confirmaron que: las evidencias de destrucción de tejido periodontal previas al tratamiento no constituyen una contraindicación para el tratamiento, la terapia ortodóncica aumenta las posibilidades de preservar y restaurar la dentadura deteriorada y el riesgo de recurrencia de un proceso patológico activo no aumenta durante la terapia con aparatos.

Se pueden mover dientes con soporte reducido sin que ello produzca pérdida de inserción, siempre y cuando esté controlada la placa subgingival. Por el contrario, la pérdida ósea será mucho mayor al mover dientes hacia defectos contaminados.

Para contrarrestar la tendencia de los aparatos ortodónticos a aumentar la acumulación de placa sobre los dientes se procura usar aparatos y mecánicas 


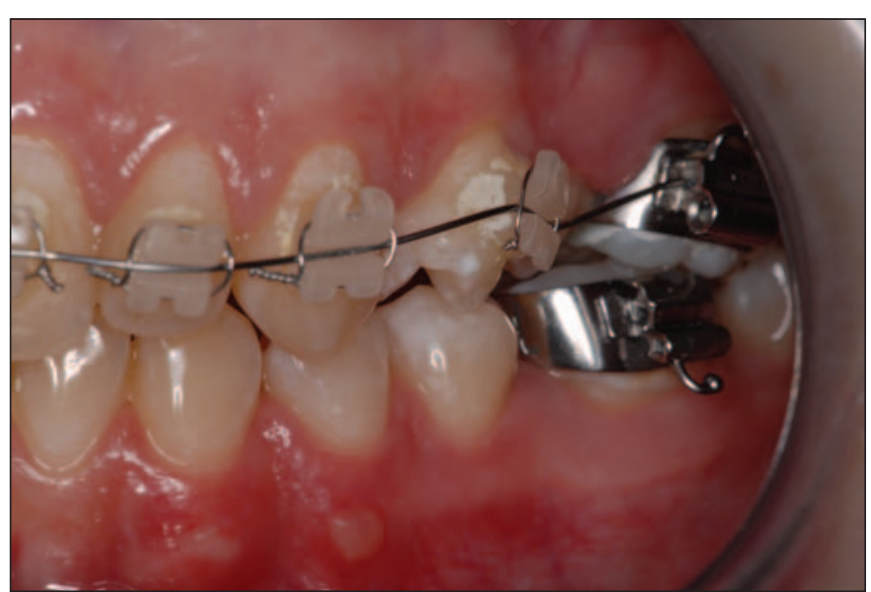

Fig. 4. Ortodoncia con brackets estéticos en paciente con alteración en la oclusión debida a la rotación de los Pre $M$, se realice la misma para devolverle la posición adecuada.

simples, y evitar los ganchos, anillos de elastómeros y los excesos de resina adhesiva por fuera de la base de los brackets.

Si los esfuerzos por mantener una higiene bucal entre buena y excelente son infructuosos, el tratamiento ortodóncico debe darse por concluido (8).

\section{Movimiento dental hacia bolsas infraóseas}

Es improbable que las fuerzas ortodóncicas en si conviertan una gingivitis en una periodontitis destructiva. La lesión inducida por la placa de la gingivitis esta confinada en el tejido conectivo supraalveolar, mientras que las reacciones tisulares ante las fuerzas ortodóncicas ocurren en el tejido conectivo situado entre la raíz y el hueso alveolar.

Dado que el movimiento dental ortodóncico hacia las bolsas infraóseas genera un riesgo alto de destrucción periodontal adicional y como las bolsas infraóseas suelen hallarse en dientes inclinados y/o alargados como resultado de la enfermedad periodontal, resulta esencial que antes de iniciar la ortodoncia se realice un tratamiento periodontal con eliminación de lesiones producidas por la placa (Fig. 1).

La reducción de la altura vertical del hueso no es contraindicación del movimiento ortodóncico. Los segundos molares inferiores pueden ser movidos hacia mesial a través de un área desdentada remodelada correspondientemente al primer molar.

También es posible el cierre de espacios en el área desdentada correspondiente al primer molar superior, pero en este caso pueden surgir como complicaciones, pérdida ósea vertical y cierta reapertura del espacio.

En cuanto al movimiento ortodóncico de dientes a través de rebordes alveolares muy atrofiados, cabe considerar la posibilidad de ganar nuevo hueso; por ejemplo, usando procedimientos de Regeneración Tisular Guiada. (9).

\section{Tipos de movimientos ortodóncicos}

Los tipos de movimientos que se pueden aplicar son:

- Extrusión.

- Intrusión.

- Rotación.

- Gresión (Fig. 6).

- Movimiento coronal controlado.

- Movimiento radicular controlado.

Describiremos la extrusión y la intrusión.

\section{Extrusión (Figs. 3-5)}

La extrusión ortodóncica de los dientes, denominada también "erupción forzada", es el movimiento menos arriesgado y más predecible para solucionar defectos óseos en dientes individuales, producto de la enfermedad periodontal o fractura dentaria, está indicada para:

- Reducir defectos intraóseos.

- Aumentar la longitud de la corona clínica en dientes aislados $(10,11)$.

En este tipo de movimientos se conserva la relación entre límite amelocementario y la cresta ósea; es decir, el hueso en conjunto con los tejidos blandos de soporte siguen al diente en su movimiento extrusivo (10-12). 


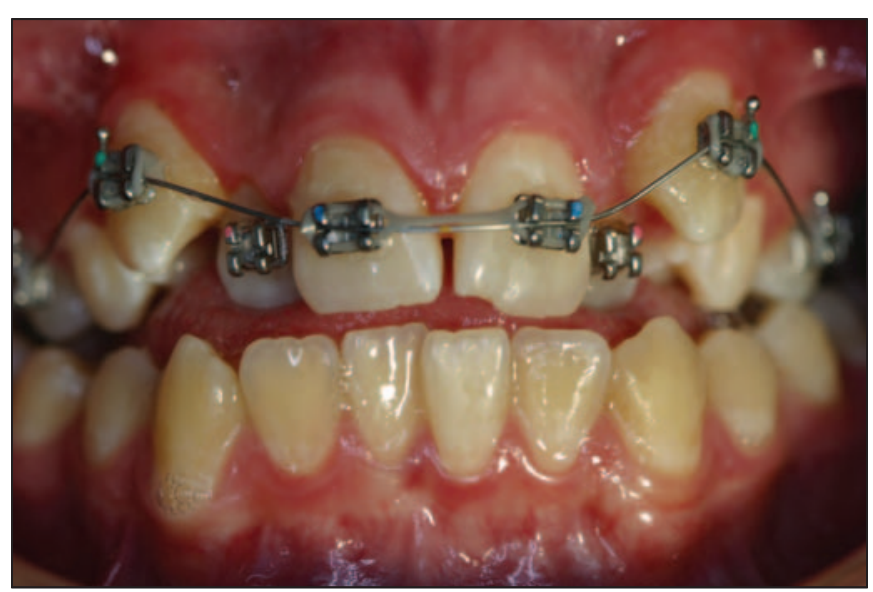

Fig. 5. Movimientos ortodóncicos (extrusión) para lograr alineación dentaria.

Estudios que realizaron una evaluación métrica del movimiento gingival asociado a la extrusión ortodóncica de los incisivos indicaron que la encía libre y la encía adherida se movieron aproximadamente en un $80-90 \%$ de la distancia total extruida, incrementándose la corona clínica y el ancho total de la encía. Sin embargo, no se modificó la posición de la unión mucogingival $(13,14)$.

El movimiento extrusivo origina un posicionamiento coronario de la inserción de tejido conectivo intacta y el defecto óseo se allana.

- Extrusión con periodonto: la extrusión ortodóncica de un único diente que necesita ser extraído

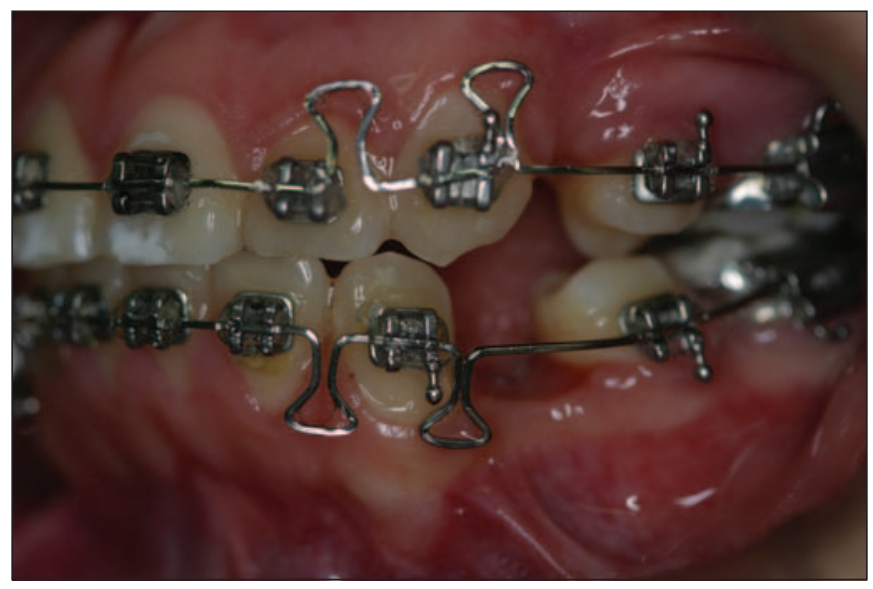

Fig. 6. Movimientos ortodóncicos para cerrar diastemas y desplazar el diente hacia la zona del defecto óseo (movimiento de gresión), ello producirá un cierre del mismo sin que ello produzca ganancia de inserción. es un método excelente para mejorar el nivel del hueso marginal antes de la instalación quirúrgica de un implante.

No sólo el hueso, sino también los tejidos blandos de sostén se moverán verticalmente con los dientes durante la extrusión ortodóncica.

Por lo tanto, la extrusión ortodóncica de un incisivo "sin esperanza" también es un método útil para el mejoramiento estético del nivel marginal de la encía asociada a la instalación de un implante.

- Extrusión fuera del periodonto: en los dientes con fractura corono radicular u otras fracturas subgingivales, el objeto de tratamiento podría ser extruir la raíz fuera del periodonto y luego colocar una corona artificial. Esto quiere decir que se desea extruir el diente sin acompañamiento del hueso; para ello la erupción forzada debe ser combinada con fibrotomía gingival cada dos semanas.

\section{Intrusión}

Es un movimiento muy peligroso, pero a veces posible y útil para mejorar la estética (especialmente en incisivos extruídos) (Fig. 1) o la función, cuando la extrusión del oponente no deja suficiente espacio para colocar un antagonista. La intrusión de dientes infectados con placa puede llevar a la formación de defectos óseos angulares y a la pérdida de inserción. Cuando la higiene bucal es incorrecta, la inclinación y la intrusión de los dientes puede desplazar la placa supragingival hasta una posición subgingival con el resultado de destrucción periodontal. Esto explica porque el raspaje subgingival es tan importante durante la fase de intrusión activa de incisivos superiores elongados, inclinados y emigrados que ocurre comúnmente en asociación con una enfermedad periodontal avanzada.

La intrusión está indicada para dientes con perdida ósea horizontal o bolsas infraóseas.

Aun en pacientes con periodonto sano la intensidad de la fuerza empleada en este tipo de movimiento no debe exceder los $15 \mathrm{~g}$ para proteger las raíces dentarias de la reabsorción.

Melsen y colaboradores demostraron clínica y experimentalmente que es posible crear una nueva inser- 
ción al realizar movimientos de intrusión en conjunto con la terapia periodontal (15).

Así también, Steffensen B. reportó buenos resultados al combinar tratamiento periodontal, movimiento ortodóncico intrusivo, contención permanente y un excelente control de placa bacteriana (16).

La fuerza aplicada se concentra en el ápice de la pieza dentaria, determinando que la reabsorción radicular sea el tipo de secuela comúnmente más observado.

Ericsson et al. sugirieron que en pacientes con mal control de placa bacteriana, el movimiento intrusivo puede desplazar la placa desde una posición supragingival a una posición subgingival, determinando destrucción periodontal caracterizada por defectos óseos angulares (17-19).

\section{Inclinación o Tipping}

Cuando se aplica una fuerza a la corona dentaria, el diente puede rotar alrededor de su centro de resistencia generándose gran compresión del ligamento periodontal a nivel de la cresta y del ápice radicular frente a fuerzas leves. De esta manera, la fuerza aplicada debe ser muy suave y el paciente debe controlar muy bien la placa para prevenir defectos óseos angulares (20).

Se ha descrito que al enderezar molares, se disminuye la PS, mejora la arquitectura gingival y se produce un menor acúmulo de placa bacteriana (11-21).

\section{CONCLUSIÓN}

Acorde a la información recabada hemos arribado a la conclusión que cada caso requiere atención individualizada, diagnóstico interdisciplinario y una planificación terapéutica que cumpla con los objetivos que el mismo demanda.

En este marco deducimos que:

- De acuerdo a la evidencia actual la salud de los tejidos periodontales es primordial en el éxito y predictibilidad del tratamiento de ortodoncia.
- La relación de ambas especialidades debe ser considerada en todas las etapas del tratamiento de ortodoncia.

- Una evaluación periodontal previa al tratamiento de ortodoncia evita o disminuye las probabilidades de secuelas periodontales desencadenadas por los movimientos ortodóncicos.

- Es importante que el ortodoncista realice su terapia con criterio periodontal.

- Cuando se ejercen fuerzas ligeras y prolongadas se comprime el ligamento periodontal y el hueso se reabsorbe de manera controlada.

- En el lado de tensión las fibras periodontales se estiran y se produce aposición ósea.

- Cuando se ejercen fuerzas excesivas se produce un aplastamiento en el lado de presión, con contacto directo entre el diente y el hueso. Ello conduce a la aparición de zonas de necrosis, reabsorción de hueso a nivel de la médula ósea y retraso en el movimiento del diente.

- Siempre que se ejerzan fuerzas leves y se mantenga una higiene bucal excelente, no hay contraindicación para mover dientes hacia áreas de hueso reducido.

\section{BIBLIOGRAFÍA}

1. Proffit W. Ortodoncia Teoría y Práctica. Bases biológicas del tratamiento ortodóncico. Madrid. España. 1994; Cap. 9:266-88.

2. Echeverria García J.J. y col. Manual SEPA de Periodoncia y Terapéutica de Implantes: Fundamentos y Guía Práctica. Periodoncia y Ortodoncia. Editorial Médica Panamericana. 2005; Sección 10, Cap. 2; 241-52.

3. Varela M. Ortodoncia Interdisciplinaria. Vo!. 1. II Ortodoncia y Periodoncia”. Océano/engon. 2004; Cap. 4. Tratamiento Ortodóncico del paciente periodontal 10:1-126.

4. Lindhe J, Karring Lang N. Periodontología Clínica e Implantología Odontológica. $4^{\mathrm{a}}$ ed. Ed. Médica Panamericana 2005;Cap. 31;777-813.

5. Berglundh T, Marineno CP, Undhe J, Thilander B $\mathcal{E}$ Liljenberg B. Periodontal tissue reactions to 
orthodontic extrusion. An experimental study in the dog. Journal of Clínical Periodontology. 1991; 18:330-6.

6. Maynard J, Wilson R. Diagnosis and management ofucogingival problems in children. Dent Clin North Am. 1980;24:683-94.

7. Lindhe J, Karring T. Anatomy of the periodontium. Clinical periodontology and implant dentistry. 3 ed. Copenhagen: Munksgard 1997: 19-68.

8. Miyasato $M$, Crigger $M$, Egelberg I. Gingival conditions in areas of minimal and appreciable width of keratinized gingival. J. Clin. PeriodontoJ 1977;4:200-9.

9. Wennstron JL. The significance of width and thickness of the gingival in orthodontic treatment. Dtsch Zahnarzd Z 1990;45:136-41.

10. Harris E; Baker W. Loss of root length and crestal bone height before and during treatment in adolescent and adult orthodontic patients. Am J Orthod Dentofacial Orthop 1990;98:463-9.

11. Álvarez F. Tratamento ortodóncico en pacientes comprometidos periodontalmente. Revista da ABO/JF 2001;10-2.

12. Vanarsdall RL. Periodontal /Orthodontic relationships. En: Graber TM, Vanarsdall RL, ed. Orthodontics: current principles and techniques. Second edn. St. Louis: Mosby 1994:800-12.

13. Zachrisson B. Interrelación Ortodoncia-Periodoncia. Cap. 25 en Lindhe, J, Periodontología Clínica e Implantología Odontológica. Tercera edición. Editorial Panamericana 2000:747-800.

14. Kajiyama K, Murakami T, Yokota S. Gingival reaction after experimentally induced extrusion of the upper incisors in monkeys. A $\mathrm{J}$ Orthod Dentofacial 1993;104:36-47.

15. Melsen B. New attachment through periodontal treatment and orthodontic intrusión. Am J Orthod Dentofacial Orthop. 1988;94:104-16.

16. Steffensen B. Orthodontic intrusive forces in the treatment of periodontally compromised incisors. A case report. Int J Periodont Rest Dent. 1993; $13: 433-41$

17. Re S, Corrente G, Abundo R, Cardaropoli D. The use of Orthodontic intrusive movement to reduce infrabony pockets in adult periodontal patients: A case report. Int. J Periodont. Rest Dent 2002; 22:365-72.

18. Ericsson I, Thailander B, Lindhe J. The effect of orthodontics tilting movements in the periodontal tissue of infected and non infected dentition in dogs. J Clin Periodontol 1977;4:278-93.

19. Ericsson I, Thailander B, Lindhe J. Periodontal condition after orthodontic tooth movement in the dog. Angle Orthodont 1978;48:210-8.

20. Hall WB. Pure mucogingival problems. Berlín: Quintessence Publishing 1984; 61.

21. Melsen, B; Agerback, N; Markenstam, G. Intrussion of incisors in adult patient with marginal bone loss. A J Orthod Dentofacial 1989; 96: 232-8.

\section{CORRESPONDENCIA}

Tortolini, Patricia

Córdoba, Argentina.

E-mail: patricia tortolini@live.com.ar 